\title{
A Comparison of hs-CRP Levels in New Diabetes Groups Diagnosed Based on FPG, 2-hPG, or HbAlc Criteria
}

\author{
Yildiz Tutuncu, ${ }^{1}$ Ilhan Satman, ${ }^{1}$ Selda Celik, ${ }^{1}$ Nevin Dinccag, ${ }^{1}$ Kubilay Karsidag, ${ }^{1}$ \\ Aysegul Telci, ${ }^{2}$ Sema Genc, ${ }^{2}$ Halim Issever, ${ }^{3}$ Jaakko Tuomilehto, ${ }^{4,5,6}$ and Beyhan Omer ${ }^{2}$ \\ ${ }^{1}$ Division of Endocrinology \& Metabolism, Department of Internal Medicine, Istanbul Medical Faculty, Istanbul University, \\ 34093 Istanbul, Turkey \\ ${ }^{2}$ Department of Clinical Biochemistry, Istanbul Medical Faculty, Istanbul University, 34093 Istanbul, Turkey \\ ${ }^{3}$ Department of Public Health, Istanbul Medical Faculty, Istanbul University, 34093 Istanbul, Turkey \\ ${ }^{4}$ Centre for Vascular Prevention, Danube-University Krems, 3500 Krems, Austria \\ ${ }^{5}$ Department of Chronic Disease Prevention, National Institute for Health and Welfare, 00271 Helsinki, Finland \\ ${ }^{6}$ Diabetes Research Group, King Abdulaziz University, Jeddah 21589, Saudi Arabia
}

Correspondence should be addressed to Ilhan Satman; satmandiabet@gmail.com

Received 3 July 2015; Revised 21 October 2015; Accepted 29 October 2015

Academic Editor: Francesco Chiarelli

Copyright (C) 2016 Yildiz Tutuncu et al. This is an open access article distributed under the Creative Commons Attribution License, which permits unrestricted use, distribution, and reproduction in any medium, provided the original work is properly cited.

Fasting plasma glucose (FPG) and hemoglobin Alc (HbAlc) have been used to diagnose new-onset diabetes mellitus (DM) in order to simplify the diagnostic tests compared with the 2-hour oral glucose tolerance test (OGTT; 2-hPG). We aimed to identify optimal cut-off points of high sensitive C-reactive protein (hs-CRP) in new-onset DM people based on FPG, 2-hPG, or HbAlc methods. Data derived from recent population-based survey in Turkey (TURDEP-II). The study included 26,499 adult people (63\% women, response rate $85 \%)$. The mean serum concentration of hs-CRP in women was higher than in men $(p<0.001)$. The people with new-onset DM based on HbAlc had higher mean hs-CRP level than FPG based and 2-hPG based DM cases. In HbAlc, 2-hPG, and FPG based new-onset DM people, cut-off levels of hs-CRP in women were 2.9, 2.1, and $2.5 \mathrm{mg} / \mathrm{L}$ [27.5, 19.7, and $23.5 \mathrm{nmol} / \mathrm{L}]$ and corresponding values in men were $2.0,1.8$, and $1.8 \mathrm{mg} / \mathrm{L}(19.0,16.9$, and $16.9 \mathrm{nmol} / \mathrm{L}$ ), respectively (sensitivity $60-65 \%$ and specificity 54-64\%). Our results revealed that hs-CRP may not further strengthen the diagnosis of new-onset DM. Nevertheless, the highest hs-CRP level observed in new-onset DM people diagnosed with HbAlc criterion supports the general assumption that this method might recognize people in more advanced diabetic stage compared with other diagnostic methods.

\section{Introduction}

The relation between chronic subclinical low-grade inflammation and insulin resistance (IR) has long been known $[1,2]$. IR is the major contributor and mediating factor in the development of type 2 DM (T2DM) along with concomitant hypertension (HT) and cardiovascular disease (CVD) $[3,4]$. The relationship between the development of $\mathrm{DM}$ and some markers of inflammation such as C-reactive protein (CRP), IL-6, fibrinogen, and PAI-1 has been described previously. Serum concentration of CRP increases in both impaired glucose tolerance (IGT) and overt T2DM [3, 5-10].
On the other hand, some studies reported that elevation of CRP is an indicator of development of T2DM [11].

Compared with the conventional OGTT (2-hPG) as recommended by $\mathrm{WHO}$ as gold standard, fasting plasma glucose (FPG) and HbAlc are more convenient, simpler, and cost-effective diagnostic methods that are currently in use for the diagnosis of T2DM [5, 12-17]. However, each test recognizes people with different metabolic features and groups who may be diagnosed by different tests but do not overlap substantially. While high postchallenge plasma glucose is a strong predictor of CVD, fasting glucose is not an independent predictor of CVD [18]. Consequently, 
further tests that will strengthen the diagnosis of DM are needed.

To the best of our knowledge, there is no previous report specifically comparing the role of hs-CRP in people with newly diagnosed DM with the criteria based on the 2-hPG, FPG, and HbAlc. Therefore, the aim of this study was to identify the optimal cut-off points of hs-CRP in new-onset (previously undiagnosed) people with DM diagnosed based on the current 2-hPG, FPG, and HbAlc diagnostic criteria. In this study, hs-CRP results obtained from a nationally representative population-based survey are being reported.

\section{Material and Methods}

Data derived from "The Turkish Epidemiology Survey of Diabetes, Hypertension, Obesity and Endocrine Diseases (TURDEP-II)," a population-based study, which was included randomly assigned 26,499 adult people from 270 urban and 270 rural centers. The field survey was performed between January and June 2010, with a participation rate of $85 \%$. The study protocol was described elsewhere [19]. A written informed consent was obtained from each participant. The study was approved by the local ethical board (Istanbul Medical Faculty Ethical Committee, 16.4.2008/699).

People with known DM or other systemic diseases who had hs-CRP levels of $10 \mathrm{mg} / \mathrm{L}(95.2 \mathrm{nmol} / \mathrm{L})$ or above were excluded from this study due to a possible infection. Final assessments included 21,485 (63.6\% women) participants. All biochemical tests including glucose, insulin, and lipid profile were measured in fasting blood samples using Roche Diagnostics Modular Autoanalyzer System (Roche Diagnostics, Germany) in the Central Biochemistry Laboratory of Istanbul Medical Faculty. Concentration of hs-CRP was analyzed by immunoturbidimetric assay (Roche/Hitachi 912, Modular P analyzers: ACN 210; CRPL3 Tina-quant C-reactive protein Gen. 3) and $\mathrm{HbAlc}$ by turbidimetric inhibition immunoassay; both the system and the laboratory have been regularly certified (Roche Diagnostics TQ HbAlc Gen. 3; NGSP Certificate of Traceability; September 2010-2011).

A detailed medical history of each participant was obtained, and measurements of anthropometry (height, weight, waist, and hip circumference) and systolic and diastolic blood pressure (SBP, DBP) were done. Body mass index (BMI), HOMA-IR (= fasting glucose $\times$ fasting insulin/405), and non-HDL-cholesterol (= total cholesterol - HDL-cholesterol) were calculated accordingly. Glomerular filtration rate (eGFR) was estimated using "Chronic Kidney Disease Epidemiology Collaboration" CKD-EPI equation [20].

2.1. Statistical Analysis. The mean values of continuous variables were compared using $t$-test. Risk factors for DM were evaluated using chi-square test; mean values by sex were compared using nonparametric Mann-Whitney $U$ test. Homogeneity of variance and normal distribution of variables were tested by Kolmogorov-Smirnov test. Pearson correlation coefficients ( $r$ values) were calculated to assess the association between hs-CRP and other laboratory parameters. Mean levels of hs-CRP in each of the new DM groups were further compared using univariate analysis after being adjusted for age, BMI, smoking and alcohol drinking, and SBP and DBP. An optimum cut-off point of hs-CRP was estimated using the receiver operating characteristic (ROC) curve and area under the curve (AUC) with 95\% CIs was calculated for each of the new DM groups that were diagnosed with FPG, $\geq 126 \mathrm{mg} / \mathrm{dL}$ (7.0 mmol/L), 2-hPG: $\geq 200 \mathrm{mg} / \mathrm{dL}(11.1 \mathrm{mmol} / \mathrm{L})$, or HbAlc: $\geq 6.5 \%(48 \mathrm{mmol} / \mathrm{mol})[13,17]$. Optimum cut-off points of hsCRP were defined for men and women, separately. As the raw data not normally distributed when log transformed, we obtained a square root transformation (sqrt) of the hs-CRP levels, and after defining the cut-off points we recalculated the squares.

Data were analyzed using SPSS for Windows (version 21.0; SPSS/IBM, Chicago, IL). A $p$ value less than 0.05 was considered statistically significant.

\section{Results}

3.1. Main Characteristics of the Study Population. Demographic characteristics and laboratory findings of women and men in TURDEP-II study are presented in Table 1. In brief, men were significantly older and had higher mean weight, waist circumference, SBP, DBP, triglycerides (TG), HDLcholesterol, and non-HDL-cholesterol values than women. Women had significantly higher BMI, hip circumference, heart rate, FPG, HbAlc, 1-hPG, 2-hPG, HDL-cholesterol, and eGFR values than men. Median (interquartile range, IQR) concentration of hs-CRP in women was significantly higher than in men (women, 1.85 [3.09] mg/L [17.6 [29.4] nmol/L], versus men, $1.47[2.33] \mathrm{mg} / \mathrm{L}[14.00[22.2] \mathrm{nmol} / \mathrm{L}], p<$ 0.001). Total serum cholesterol, fasting serum insulin, and HOMA-IR values did not differ between men and women (Table 1).

3.2. Correlation Analysis of $h s$-CRP. There was a positive correlation between hs-CRP levels and age, BMI, waist, hip, SBP, DBP, pulse, FPG, HbAlc, 1-hPG, 2-hPG, TG, non-HDLcholesterol, and HOMA-IR; and there was a negative correlation with HDL-cholesterol and eGFR. When we repeated the analysis after controlling for HT, age, sex, smoking and alcohol use, BMI, and waist circumference, the positive correlations between hs-CRP levels and HbAlc, 1-hPG, 2hPG, TG, non-HDL-cholesterol, eGFR, and HOMA-IR and the negative correlation with HDL-cholesterol and creatinine remained significant (Table 2).

3.3. Mean hs-CRP in Newly Diagnosed DM Groups and Sex Difference. Among people with new DM, the highest hs-CRP level was in the group detected by HbAlc criterion (hs-CRP median [IQR]; HbAlc: 3.45 [3.82] mg/dL, 32.9 [36.4] nmol/L; 2-hPG: 2.7 [3.14] mg/dL, 25.4 [29.9] nmol/L; and FPG: 2.4 [3.0] $\mathrm{mg} / \mathrm{dL}, 22.4$ [28.5] nmol/L, data not shown).

High sensitive CRP level was significantly higher in women than men with newly diagnosed DM groups based on 2-hPG, FPG, and HbAlc criteria. Among the newly diagnosed DM groups, the median [IQR] level of hs-CRP was highest in those detected with HbAlc in both genders (HbAlc-group: women: 4.0 [4.1] mg/dL, 38.4 [39.1] nmol/L; 
TABLE 1: Clinical characteristics and laboratory findings of TURDEP-II study population*.

\begin{tabular}{|c|c|c|c|}
\hline Parameter & Women $(n=13,676)$ & $\operatorname{Men}(n=7,809)$ & $p$ value \\
\hline Age (year) & $43(15)$ & $44.7(15.6)$ & $<0.000001$ \\
\hline BMI $\left(\mathrm{kg} / \mathrm{m}^{2}\right)$ & $28.6(5.7)$ & $27.2(4.3)$ & $<0.000001$ \\
\hline Waist $(\mathrm{cm})$ & $91.3(14.5)$ & $96.4(12.8)$ & $<0.000001$ \\
\hline Hip $(\mathrm{cm})$ & $108.6(13.2)$ & $105.1(10.3)$ & $<0.000001$ \\
\hline SBP $(\mathrm{mmHg})$ & $118(27)$ & $120(22)$ & 0.000008 \\
\hline $\mathrm{DBP}(\mathrm{mmHg})$ & $74(13)$ & $75(12)$ & $<0.000001$ \\
\hline HR (beat/min) & $79.5(8.7)$ & $78.3(9.2)$ & $<0.000001$ \\
\hline $\begin{array}{l}\text { hs-CRP }(\mathrm{mg} / \mathrm{L})^{* *} \\
{[\mathrm{nmol} / \mathrm{L}]}\end{array}$ & $\begin{array}{l}1.85(3.09) \\
17.6(29.4)\end{array}$ & $\begin{array}{l}1.47(2.33) \\
14.0(22.2)\end{array}$ & $<0.000001$ \\
\hline $\mathrm{FPG}(\mathrm{mmol} / \mathrm{L})$ & $5.5(1.03)$ & $5.48(1.18)$ & 0.000449 \\
\hline HbAlc (mmol/mol) [\%] & $\begin{array}{c}38(7) \\
{[5.6(0.6)]}\end{array}$ & $\begin{array}{c}37(8) \\
{[5.5(0.7)]}\end{array}$ & 0.003493 \\
\hline 1-hPG (mmol/L) & $8.9(2.5)$ & $8.76(2.52)$ & 0.000013 \\
\hline 2-hPG (mmol/L) & $7.2(2.1)$ & $6.34(2.04)$ & $<0.000001$ \\
\hline Creatinine $(\mu \mathrm{mol} / \mathrm{L})$ & $64.0(11.0)$ & $82.0(14.4)$ & $<0.000001$ \\
\hline Triglycerides $(\mathrm{mmol} / \mathrm{L})$ & $1.4(0.8)$ & $1.67(1.15)$ & $<0.000001$ \\
\hline HDL-cholesterol (mmol/L) & $1.3(0.3)$ & $1.09(0.27)$ & $<0.000001$ \\
\hline Non-HDL-cholesterol (mmol/L) & $3.5(1.0)$ & $3.69(1.01)$ & $<0.000001$ \\
\hline Fasting insulin $(\mathrm{pmol} / \mathrm{L})$ & $56.4(49.6)$ & $56.9(60.5)$ & 0.570725 \\
\hline HOMA-IR & $1.9(2.9)$ & $2.0(3.1)$ & 0.258439 \\
\hline $\begin{array}{l}\mathrm{eGFR}^{* * *}\left(\mathrm{~mL} / \mathrm{min} \text { per } 1.73 \mathrm{~m}^{2}\right) \\
{\left[\mathrm{mL} / \mathrm{s} \text { per } 1.73 \mathrm{~m}^{2}\right]}\end{array}$ & $\begin{array}{l}101.0(17.4) \\
{[0.14(0.04)]}\end{array}$ & $\begin{array}{c}98.8(16.9) \\
{[0.13(0.04)]}\end{array}$ & $<0.000001$ \\
\hline
\end{tabular}

${ }^{*}$ mean $(\mathrm{SD}) ;{ }^{* *}$ median $(\mathrm{IQR}) ;{ }^{* * *} \mathrm{CKD}$-EPI equation.

1-hPG, oral glucose tolerance test 1st hour plasma glucose; 2-hPG, oral glucose tolerance test 2nd hour plasma glucose; BMI, body mass index; CKD-EPI, Chronic Kidney Disease Epidemiology Collaboration; DBP, diastolic blood pressure; eGFR, estimated glomerular filtration rate; FPG, fasting plasma glucose; HbAlc, hemoglobin Alc; HDL-cholesterol, high density lipoprotein cholesterol; HOMA-IR, homeostasis model of assessment; HR, heart rate; hs-CRP, high sensitive C-reactive protein; IQR, interquartile range; SBP systolic blood pressure.

men: 2.7 [3.1] mg/dL, 25.9 [29.1] nmol/L; FPG group: women: $3.3[4.1] \mathrm{mg} / \mathrm{dL}, 31.1[39.3] \mathrm{nmol} / \mathrm{L} ; \mathrm{men}: 2.4[3.0] \mathrm{mg} / \mathrm{dL}, 22.4$ [28.5] nmol/L; and 2-hPG group: women: $2.8[3.3] \mathrm{mg} / \mathrm{dL}$, $26.5[31.3] \mathrm{nmol} / \mathrm{L}$; men: 2.4 [2.8] mg/dL, 23.3 [26.9] nmol/L).

Sex differences in hs-CRP did not change after the data adjusted with respect to age, BMI, waist circumference, and HT; the mean hs-CRP was highest in newly diagnosed patients based on HbAlc criterion in both sexes. Again, the average hs-CRP levels of women were higher than men (Table 3). In women with newly diagnosed DM based on FPG, mean hs-CRP level was comparable to those diagnosed with 2-hPG but lower than the group diagnosed with HbAlc $(p=0.000032)$. Women with newly detected DM based on 2-hPG had also lower mean hs-CRP than those detected with HbAlc $(p<0.000001)$. In contrast, men with newly detected DM based on FPG criterion had lower mean hs-CRP than those diagnosed with 2-hPG $(p=0.017)$ and HbAlc ( $p=0.003$ ) but mean hs-CRP levels were comparable in 2hPG and HbAlc based new DM groups (Table 3).

3.4. Optimal Cut-Off Points and AUCs of hs-CRP for Newly Diagnosed DM Groups. The specificity and sensitivity of the optimal cut-off points for hs-CRP to detect DM in women were for the FPG group, $60 \%$ and $57 \%$ for $2.5 \mathrm{mg} / \mathrm{L}$ (23.6 nmol/L), 2-hPG group, $60 \%$ and $54 \%$ for $2.1 \mathrm{mg} / \mathrm{L}$
(19.7 nmol/L), and $65 \%$ and $64 \%$ for HbAlc group, $2.9 \mathrm{mg} / \mathrm{L}$ $(27.5 \mathrm{nmol} / \mathrm{L})$. In men the corresponding specificity and sensitivity values were as follows: FPG group: $60 \%$ and $57 \%$ for $1.8 \mathrm{mg} / \mathrm{L}(16.9 \mathrm{nmol} / \mathrm{L}) ; 2-\mathrm{hPG}$ group: $60 \%$ and $57 \%$ for $1.8 \mathrm{mg} / \mathrm{L}(16.9 \mathrm{nmol} / \mathrm{L})$; and HbAlc group: $65 \%$ and $60 \%$ for $2.0 \mathrm{mg} / \mathrm{L}(19.0 \mathrm{nmol} / \mathrm{L})$ (ROC curves Figure 1 and Table 4). The largest AUC value for hs-CRP to detect DM was found in women and men when using HbAlc (women: 0.700; men: 0.656 ).

The positive and negative predictive values (PPV and NPV) corresponding to the above-mentioned cut-points of hs-CRP in women were calculated as $58 \%$ and $59 \%$ for FPG, $57 \%$ and $58 \%$ for 2 -hPG, and $64 \%$ and $65 \%$ for HbAlc and in men were $58 \%$ and $59 \%$ for FPG, $58 \%$ and $59 \%$ for 2 -hPG, and $61 \%$ and $61 \%$ for HbAlc. The best results for PPV and NPV were obtained by the HbAlc method.

\section{Discussion}

Our current population-based study identified 1,727 people with newly diagnosed DM based on at least one of the three methods. However, the people identified to have DM were substantially different for each of the three methods. In other words, the concordance rate for DM among the different methods of glycaemia testing was low. There are probably 
TABLE 2: Pearson correlation analysis (unadjusted and adjusted) of hs-CRP and other parameters.

\begin{tabular}{|c|c|c|c|c|c|}
\hline $\begin{array}{l}\text { Unadjusted Pearson } \\
\text { correlation: hs-CRP versus }\end{array}$ & $r$ & $p$ & $\begin{array}{l}\text { Controlled for age, sex, smoking, alcohol, } \\
\text { BMI, waist, HT, and medications: hs-CRP } \\
\text { versus }\end{array}$ & $r$ & $p$ \\
\hline Age & 0.18 & $<0.001$ & $\mathrm{HbAlc}$ & 0.08 & $<0.001$ \\
\hline BMI & 0.37 & $<0.001$ & 1-hPG & 0.07 & 0.001 \\
\hline Waist & 0.30 & $<0.001$ & 2-hPG & 0.07 & $<0.011$ \\
\hline Hip & 0.29 & $<0.001$ & Creatinine & -0.05 & 0.001 \\
\hline SBP & 0.12 & $<0.001$ & Triglycerides & 0.09 & $<0.001$ \\
\hline DBP & 0.13 & $<0.001$ & Total cholesterol & 0.05 & 0.018 \\
\hline HR & 0.07 & $<0.001$ & HDL-cholesterol & -0.06 & 0.002 \\
\hline FPG & 0.12 & $<0.001$ & Non-HDL-cholesterol & 0.07 & 0.001 \\
\hline HbAlc & 0.19 & $<0.001$ & Fasting insulin & 0.07 & $<0.001$ \\
\hline 1-hPG & 0.19 & $<0.001$ & HOMA-IR & 0.06 & 0.002 \\
\hline 2-hPG & 0.15 & $<0.001$ & eGFR & 0.05 & 0.014 \\
\hline Creatinine & -0.12 & 0.001 & & & \\
\hline HDL-cholesterol & -0.10 & $<0.001$ & & & \\
\hline Non-HDL-cholesterol & 0.20 & $<0.001$ & & & \\
\hline Fasting insulin & 0.13 & $<0.001$ & & & \\
\hline HOMA-IR & 0.11 & $<0.001$ & & & \\
\hline eGFR & -0.13 & $<0.001$ & & & \\
\hline
\end{tabular}

1-hPG, oral glucose tolerance test 1st hour plasma glucose; 2-hPG, oral glucose tolerance test 2nd hour plasma glucose; BMI, body mass index; DBP, diastolic blood pressure; eGFR, estimated glomerular filtration rate; FPG, fasting plasma glucose; HbAlc, hemoglobin Alc; HDL-cholesterol, high density lipoprotein cholesterol; HOMA-IR, homeostasis model of assessment; HR, heart rate; hs-CRP, high sensitive C-reactive protein; HT, hypertension; SBP, blood pressure.

TABLE 3: hs-CRP levels in women and men with newly detected DM using the FPG, 2-hPG, or HbAlc criteria* .

\begin{tabular}{|c|c|c|c|c|}
\hline \multirow{3}{*}{ Diagnostic methods } & \multicolumn{4}{|c|}{ hs-CRP; mg/L [nmol/L] } \\
\hline & \multicolumn{2}{|c|}{ Women } & \multicolumn{2}{|c|}{ Men } \\
\hline & Mean (SEM), $(n)$ & $95 \% \mathrm{CI}$ & Mean (SEM), $(n)$ & $95 \% \mathrm{CI}$ \\
\hline $\begin{array}{l}\text { FPG-DM } \\
(n=477)\end{array}$ & $\begin{array}{c}3.3(0.1),(n=309) \\
{[31.5(1.3)]}\end{array}$ & $\begin{array}{c}3.0-3.5 \\
{[28.6-33.6]}\end{array}$ & $\begin{array}{c}2.5(0.2)(n=168) \\
{[23.4(1.6)]}\end{array}$ & $\begin{array}{c}2.13-2.80 \\
{[20.3-26.6]}\end{array}$ \\
\hline $\begin{array}{l}\text { 2-hPG-DM } \\
(n=653)\end{array}$ & $\begin{array}{c}3.2(0.1)(n=483) \\
{[30.5(1.0)]}\end{array}$ & $\begin{array}{c}3.0-3.40 \\
{[28.5-32.4]}\end{array}$ & $\begin{array}{c}3.0(0.2)(n=170) \\
{[29.0(1.6)]}\end{array}$ & $\begin{array}{c}2.7-3.4 \\
{[25.9-32.1]} \\
\end{array}$ \\
\hline $\begin{array}{l}\text { HbAlc-DM } \\
(n=597)\end{array}$ & $\begin{array}{c}4.0(0.1)(n=356) \\
{[38.5(1.2)]}\end{array}$ & $\begin{array}{c}3.8-4.3 \\
{[36.2-40.8]}\end{array}$ & $\begin{array}{c}3.1(0.1)(n=241) \\
{[29.8(1.3)]}\end{array}$ & $\begin{array}{c}2.9-3.40 \\
{[27.2-32.4]}\end{array}$ \\
\hline \multirow{3}{*}{ Post hoc comparisons } & \multicolumn{2}{|c|}{ FPG-DM versus 2-hPG-DM, $p=0.698$} & \multicolumn{2}{|c|}{ FPG-DM versus 2-hPG-DM, $p=0.017$} \\
\hline & \multicolumn{2}{|c|}{ FPG-DM versus HbAlc-DM, $p=0.000032$} & \multicolumn{2}{|c|}{ FPG-DM versus $\mathrm{HbAlc-DM,} p=0.003$} \\
\hline & \multicolumn{2}{|c|}{ 2-hPG-DM versus HbA1c-DM, $p<0.000001$} & \multicolumn{2}{|c|}{ 2-hPG-DM versus HbAlc-DM, $p=0.0695$} \\
\hline
\end{tabular}

${ }^{*}$ Adjusted for age, BMI, waist, and hypertension (HT). Women: $p<0.000001$; men: $p=0.008$.

several reasons for this discrepancy. Characteristics of the people with DM and their risk factors may vary by the method used for the detection of DM.

Several studies have suggested that inflammation is associated with IR that takes part in the pathogenesis of T2DM and atherosclerotic disease $[1-4,6]$. Environmental factors such as infections, overnutrition, and lack of physical activity are believed to contribute serum CRP levels although the mechanism is not properly understood. On the other hand, hyperglycaemia per se may induce inflammation and this may enhance the development of DM [21, 22].

Festa et al. demonstrated that people who developed DM (detected by an OGTT) had higher baseline serum CRP levels than those who did not develop DM [23]. There was a linear increasing trend in the incidence of DM as the baseline CRP quartile increased [23]. In Pizarra prospective study, people with baseline hs-CRP $\geq 3 \mathrm{mg} / \mathrm{L}(\geq 28.6 \mathrm{nmol} / \mathrm{L})$ developed DM [24]. In our previous report, we demonstrated a linear increasing trend for hs-CRP levels from normal glucose tolerance through impaired fasting glucose (IFG), IGT, and new DM [19].

A recent meta-analysis including 18 prospective studies demonstrated that high baseline CRP levels associated with future T2DM diagnosed based on FPG and/or 2-hPG criteria [25]. All these findings support the chronic low-grade inflammation hypothesis in the development of DM. 

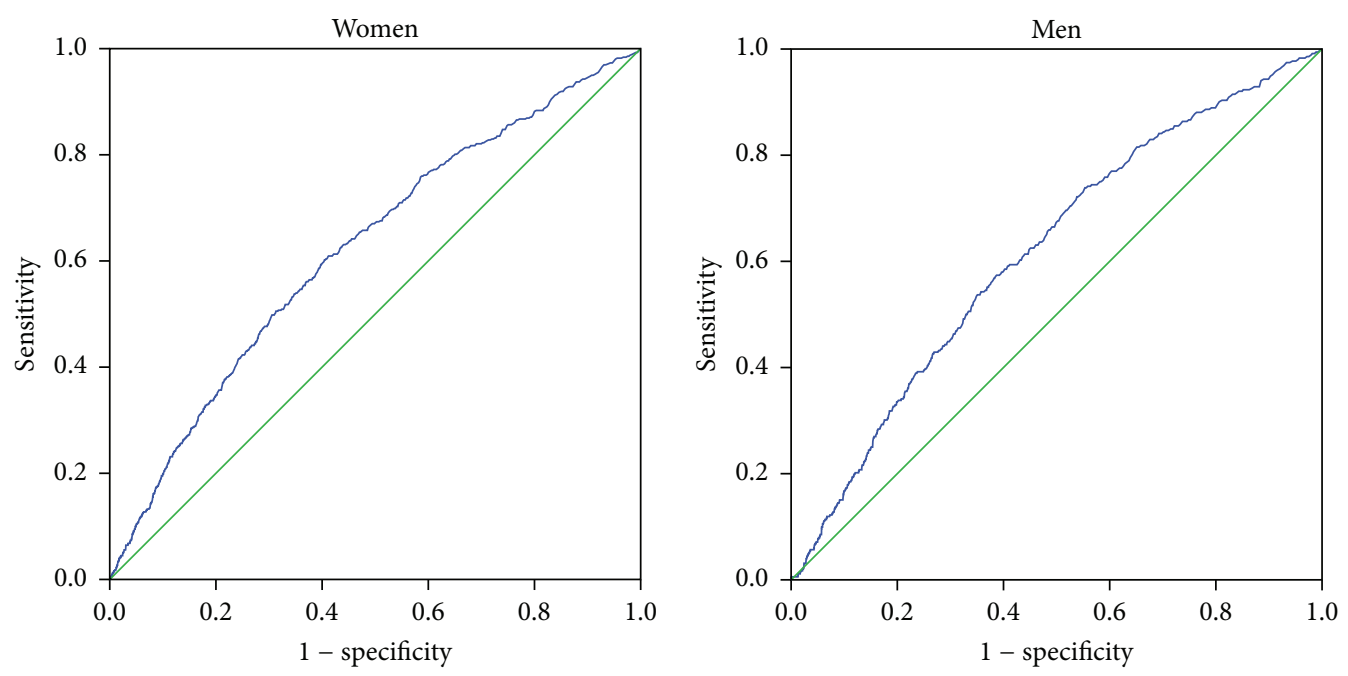

(a)
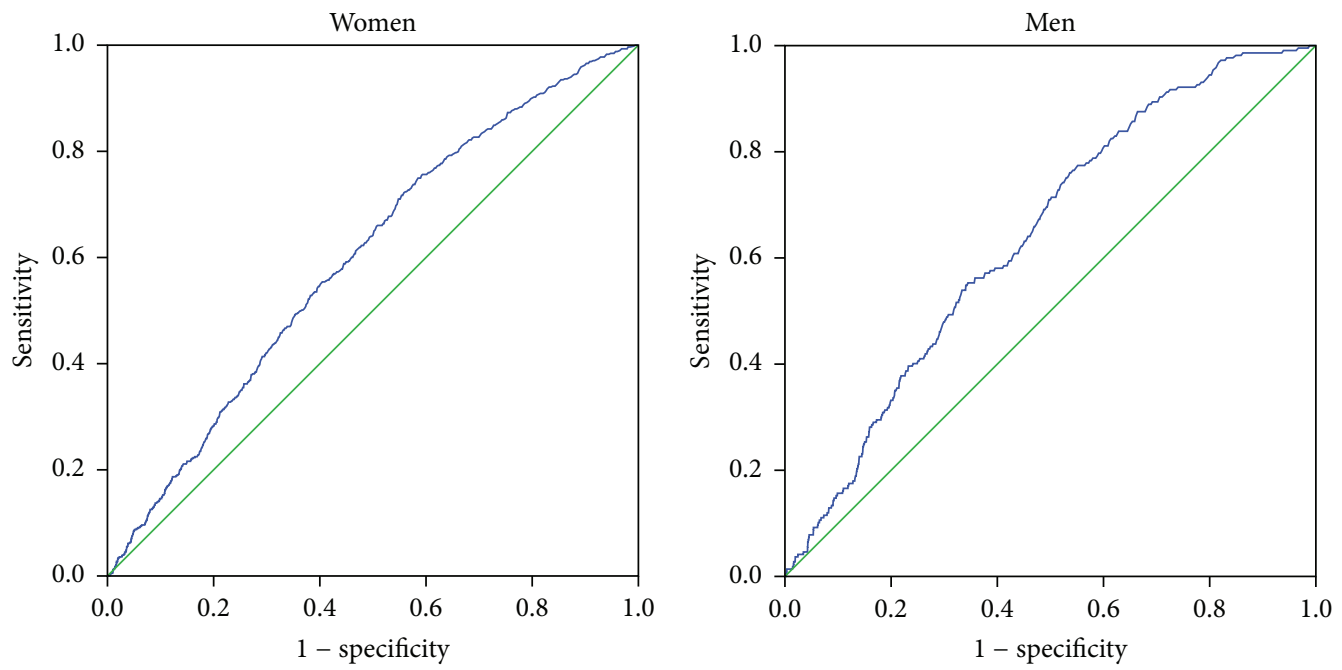

(b)
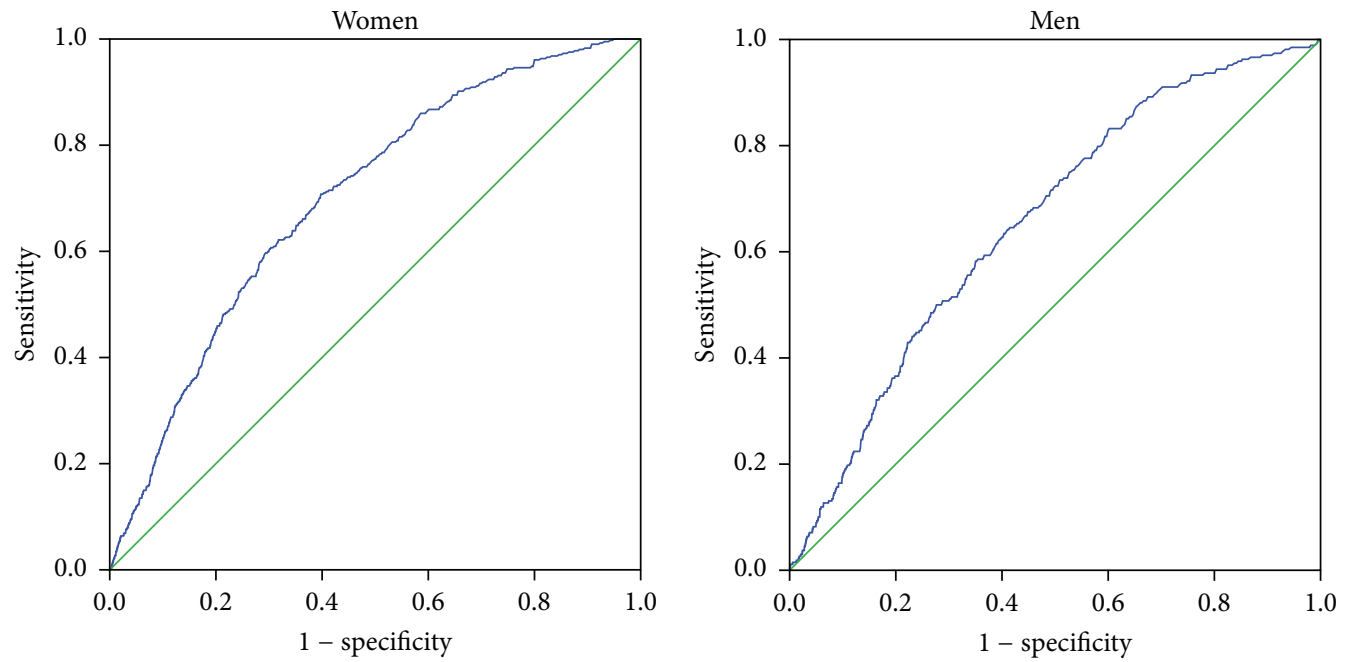

(c)

FIGURE 1: ROC curves in women and men new-onset DM groups diagnosed with (a) FPG, (b) 2-hPG, and (c) HbAlc criteria (ROC: receiver operating characteristic curve; FPG: fasting plasma glucose; 2-hPG: 2-hour plasma glucose during OGTT; HbAlc: hemoglobin Alc). 
TABLE 4: (a) The area under the curve (AUC) and (b) the best cut-off points for hs-CRP to identify newly detected DM based on the FPG, 2-hPG, or HbAlc criteria in women and men.

(a)

\begin{tabular}{lccccr}
\hline Method & Gender & AUC & SEM & $p$ & 95\% CI \\
\hline \multirow{2}{*}{ FPG } & Women & 0.622 & 0.012 & $<0.001$ & $0.598-0.646$ \\
& Men & 0.617 & 0.015 & $<0.001$ & $0.588-0.646$ \\
\hline \multirow{2}{*}{ 2-hPG } & Women & 0.599 & 0.011 & $<0.001$ & $0.577-0.621$ \\
& Men & 0.640 & 0.017 & $<0.001$ & $0.606-0.673$ \\
\multirow{2}{*}{ HbAlc } & Women & 0.700 & 0.012 & $<0.001$ & $0.676-0.723$ \\
& Men & 0.656 & 0.016 & $<0.001$ & $0.625-0.686$ \\
\hline
\end{tabular}

(b)

\begin{tabular}{|c|c|c|c|c|c|c|}
\hline \multirow{3}{*}{ Method } & \multicolumn{6}{|c|}{ Best cut-off points } \\
\hline & \multicolumn{3}{|c|}{ Women } & \multicolumn{3}{|c|}{ Men } \\
\hline & hs-CRP mg/L [nmol/L] & Sensitivity & Specificity & hs-CRP mg/L [nmol/L] & Sensitivity & Specificity \\
\hline FPG & $2.5[23.6]$ & 0.60 & 0.57 & $1.8[16.9]$ & 0.60 & 0.57 \\
\hline 2-hPG & $2.1[19.7]$ & 0.60 & 0.54 & $1.8[16.9]$ & 0.60 & 0.57 \\
\hline HbAlc & $2.9[27.5]$ & 0.65 & 0.64 & $2.0[19.0]$ & 0.60 & 0.62 \\
\hline
\end{tabular}

In our study, we found a positive correlation between hsCRP levels and all glycaemia and IR parameters. However, after adjustment for age, sex, smoking, BMI, waist, and HT, positive correlations were maintained with HbAlc, 1-hPG and 2-hPG, fasting insulin, and HOMA-IR but not with FPG. In their later report Festa et al. stated that postchallenge glucose but not FPG was strongly correlated with baseline CRP [26]. Other studies have also shown an association between CRP and DM, which remained significant after adjusting for BMI or other covariates [25]. Our findings and others suggested that adiposity is not sufficient to explain the relationship between high levels of inflammatory markers and increased DM risk. The predictive value of hs-CRP did not seem to be fully independent of obesity in several $[3,23,24,27,28]$ but not all studies [7, 9, 10, 22].

Our results showed that among people with new DM the highest hs-CRP levels were obtained in those identified with the HbAlc criterion. HbAlc elevation at diagnosis is an indication of overt DM, but in a more advanced stage compared with new-onset DM detected with the FPG or 2hPG criteria. As we did show a positive correlation between hs-CRP and HbAlc, it has been reported that people with DM with poorer glycaemic control had higher CRP levels [8]. Some commonly used medications like aspirin and statin may synergistically reduce serum CRP concentrations $[29,30]$. In the present study, we excluded people with known systemic disease and those who self-reported regularly using such medications; however, we may not ascertain all people using aspirin and/or statin.

Aronson et al. reported that CRP levels among middleaged people were higher in those with DM and IFG when compared with the healthy subjects [21]. Similar to our findings showing women had higher hs-CRP levels than men regardless of having $\mathrm{DM}$ or not, the ADOPT investigators have reported that hs-CRP levels in women were higher than in men in both with and without the metabolic syndrome
(MS) [31]. They reported a positive correlation between hsCRP and HbAlc, BMI and HOMA-IR and the number of MS components in people with new DM [31]. In Women's Health Study, the incidence of DM was four times higher in women with hs-CRP levels in the upper quartile in comparison with those with hs-CRP levels in the lowest quartile [32].

$\mathrm{Wu}$ and coworkers reported that high levels of hs-CRP were correlated with high levels of HbAlc and FPG in men and with only FPG in women [33]. A similar finding was also reported by Festa et al. [3]. Other studies reported strong correlations between hs-CRP and fasting insulin [7], HOMAIR [28], and FPG [21,34] and an inverse correlation with CRP and HDL-cholesterol [3, 21]; all were confirmed in our study.

We estimated the optimal cut-off hs-CRP and AUC-CRP with 95\% CIs for DM for each of the three diagnostic methods separately. To the best of our knowledge, this is the first study aiming at determining hs-CRP cut-off points indicating new DM compared with each of the three methods assessing hyperglycaemia. The highest cut-off point for hs-CRP was obtained with HbAlc based new DM detection compared to FPG and 2-hPG methods. In fact we previously showed that new DM group detected with HbAlc has a more advanced metabolic disorder (higher BMI, waist, blood pressure, nonHDL-cholesterol, triglycerides, and insulin but lower HDLcholesterol) than other new DM groups detected with FPG or 2-hPG [35].

den Engelsen et al. attempted to find a cut-off point for hs-CRP that would indicate the presence of the MS [36]. If hs-CRP cut-off point was set at $3 \mathrm{mg} / \mathrm{L}(28.6 \mathrm{nmol} / \mathrm{L})$, the sensitivity and specificity were $72 \%$ and $37 \%$; at this point PPV and NPV were $42 \%$ and $67 \%$ [36]. In another study performed in a Japanese population, a cut-off point of hs-CRP of $0.65 \mathrm{mg} / \mathrm{L}(6.2 \mathrm{nmol} / \mathrm{L})$ for FPG $100 \mathrm{mg} / \mathrm{dL}$ $(5.6 \mathrm{mmol} / \mathrm{L})$ or higher was capable of defining the MS with a $100 \%$ sensitivity and $77 \%$ specificity in women and with a $65 \%$ sensitivity and $63 \%$ specificity in men [37]. In our study 
the optimum cut-point of hs-CRP of $2.5 \mathrm{mg} / \mathrm{L}(23.6 \mathrm{nmol} / \mathrm{L})$ in women and $1.8 \mathrm{mg} / \mathrm{L}(16.9 \mathrm{nmol} / \mathrm{L})$ in men for $\mathrm{FPG}$ $\geq 126 \mathrm{mg} / \mathrm{dL}(7.0 \mathrm{mmol} / \mathrm{L})$ or higher was capable of defining the new DM with a $60 \%$ sensitivity and $57 \%$ specificity in both genders. The optimum cut-point for HbAlc $6.5 \%$ and over was $2.9 \mathrm{mg} / \mathrm{L}(27.5 \mathrm{nmol} / \mathrm{L})$ in women with a $65 \%$ sensitivity and $64 \%$ specificity and $2.0 \mathrm{mg} / \mathrm{L}(19.0 \mathrm{nmol} / \mathrm{L})$ in men with a $60 \%$ sensitivity and $62 \%$ specificity, and the largest AUC value for hs-CRP to detect new DM was found in women and men when using HbAlc (women: 0.700; men: 0.656). These high cut-off points of CRP may be related with the more advanced diabetic state as compared to FPG or 2-hPG based detected cases.

One of the greatest strengths of the present study is its national representative sampling with a large sample size and wide age range. In addition, this is the first study where all three currently proposed methods (2-hPG, FPG, and HbAlc) were used to define DM and each of them was compared with the inflammation marker, hs-CRP. The major limitations are the cross-sectional design and somewhat higher participation rate in women, controlled in the data analyses.

In brief, an hs-CRP level $\geq 1.8 \mathrm{mg} / \mathrm{L}(16.9 \mathrm{nmol} / \mathrm{L})$ generally detects more than half of the people with new DM. External validation of our findings needs to be carried out in additional studies in other populations with reasonably large sample size before these findings can be generalized.

\section{Conclusions}

Our results revealed that hs-CRP may not further strengthen the diagnosis of new-onset DM. However, the highest hs-CRP among people with new DM was found in those identified with the HbAlc criterion. This suggests that high HbAlc may recognize new DM cases at a more advanced stage than FPG or 2-hPG in an OGTT. Clinical implications of this finding deserve further evaluation. It would be important to find out if people with newly detected $\mathrm{DM}$ with high hs-CRP require a more intensive therapy than those with low hs-CRP.

\section{Disclosure}

The funding agencies had no role in the design and conduct of the study; the collection, management, analysis, and interpretation of the data; or the preparation, review, or approval of the paper.

\section{Conflict of Interests}

The authors declare that they have no conflict of interests.

\section{Authors' Contribution}

Ilhan Satman designed the study. Yildiz Tutuncu and Ilhan Satman completed the main data analysis and the preparation of the paper. Selda Celik, Nevin Dinccag, Kubilay Karsidag, Aysegul Telci, Sema Genc, Jaakko Tuomilehto, and Beyhan Omer contributed to interpretation of the data and preparation of the paper. Halim Issever contributed to statistical analysis and interpretation of the results. All authors read and approved the final paper.

\section{Acknowledgments}

This study was funded by the Turkish Scientific and Technical Research Council, TUBITAK (Project no. 109S166), The Society of Endocrinology and Metabolism of Turkey (SEMT), the Association of Diabetes Obesity and Metabolism (DOM), and Istanbul University Scientific Research Fund (Project nos. 6417 and 6418). The authors wish to thank the members of the TURDEP-II Study Group and other employees of the Ministry of Health for their valuable contribution. The authors also acknowledge Roche Diagnostics, BMS, Sanofi, Novo Nordisk, Eli Lilly, Novartis, Pfizer, Bayer Diagnostics, Medtronic, Boehringer-Ingelheim, Merck Sharp \& Dohme, Sanofi-Pasteur, Astra Zeneca, Bilim Ilac, Becton-Dickinson, Merck Serono, Takeda, Abbott Medical, Tamek, Tetra-Pak, NUD, and NFGUD for providing unrestricted and unconditioned grants for the study. Special thanks are due to Monitor CRO for logistic assistance during the field survey and data entry. The authors are grateful to Sibel Kalaca for comments on the paper. Members of the TURDEP-II Study Group. Investigators-I. Satman, N. Dinccag, K. Karsidag, T. Yilmaz, F. Alagol, B. Omer, S. Kalaca, Y. Tutuncu, N. C. Ozbey, H. Boztepe, S. Genc, S. Gedik, F. Turker, A. Telci, B. Canbaz, R. S. Calis, and Y. M. Oltulu; the Ministry of Health-B. Cakir. B. Keskinkilic, R. Imamecioglu, N. Yardim, and N. Coban; adviser-J. Tuomilehto; field survey-A. I. Dokucu, D. Ozkul, H. Karabulut, I. Topcu, S. B. Kartal, S. Cinar, A. Uzunoglu, T. Kirtas, E. Ucuncuoglu, O. Altinkaynak, and C. Kahveci (Istanbul); Y. C. Sahin, E. Saydam, D. Gurgenyatagi, G. Hamzaoglu, and M. Demirci (Samsun); M. Dereli (Trabzon); A. Akkaya, Y. Bas, G. Ozdemir, Y. C. Guneyler, and M. Derin (Bursa); A. O. Candan (Izmir); M. Okudan (Antalya); N. N. Colak (Adana); M. Akoz (Gaziantep); M. Gundogdu (Denizli); E. Gurgut (Erzurum); G. Kuzu, H. B. Zengin, and D. Bozkurt (Malatya); D. Bilici and M. Zafer (Diyarbakir); M. Erogul, A. Sag, A. Simsek, A. Altin, and U. Cakar (Eskisehir); T. Ozdemir and Y. Gokce (Ankara); A. Sakir, O. Unsal, N. Uyar, and S. Akdeniz (Konya); universities and trainingresearch hospitals-S. Akalin, E. Ozer, Y. Altuntas, M. Sargin, A. Sengul, S. Salman, F. Salman, and A. Turkmen (Istanbul); S. Imamoglu and O. O. Gul (Bursa); C. Yilmaz, F. Saygili, S. Cetinkalp, F. Bayraktar, S. Yesil, A. Comlekci, M. Bahceci, and G. G. Oruk (Izmir); M. Balci. H. Altunbas and B. U. Koyuncu (Antalya); T. Tetiker (Adana); M. Araz and E. Akarsu (Gaziantep); A. Tuzcu (Diyarbakir); I. Sahin and A. C. Sertkaya (Malatya); G. Akcay (Erzurum); A. Kaya and S. Gonen (Konya); M. Arslan, S. Gullu, G. Ayvaz, A. Corakci, M. Kutlu, T. Erbas, M. Bayraktar, N. Baskal, B. Cakir, and S. Guler (Ankara); B. Efe, A. Akalin, and G. Yorulmaz (Eskisehir); F. Akin. E. Yerlikaya (Denizli); A. Atmaca and E. K. Kan (Samsun); C. Erem, H. O. Ersoz, I. Nuhoglu, and E. Algun (Trabzon); Monitor CRO-S. Misirlioglu, G. Betin, E. Koruyucu, A. Calisgan, O. Akbas, T. Devlen, G. Okyay, E. Erdem, C. Sarp, F. Durgun, C. Akbas, S. Fesligil, and M. Sasmaz; other supporters-O. Halil, H. Kirmaz, H. Oget, C. 
Sengor, B. Sakkaoglu, M. Tanberk, M. Satman, A. Koroglu, Y. Ersahin, S. Uygur, and A. Aydin.

\section{References}

[1] J. C. Pickup and M. A. Crook, "Is type II diabetes mellitus a disease of the innate immune system?" Diabetologia, vol. 41, no. 10, pp. 1241-1248, 1998.

[2] M. Y. Donath and S. E. Shoelson, "Type 2 diabetes as an inflammatory disease," Nature Reviews Immunology, vol. 11, no. 2, pp. 98-107, 2011.

[3] A. Festa, R. D’Agostino Jr., G. Howard, L. Mykkänen, R. P. Tracy, and S. M. Haffner, "Chronic subclinical inflammation as part of the insulin resistance syndrome: the insulin resistance atherosclerosis study (IRAS)," Circulation, vol. 102, no. 1, pp. 4247, 2000.

[4] P. M. Ridker, J. E. Buring, N. R. Cook, and N. Rifai, "Creactive protein, the metabolic syndrome, and risk of incident cardiovascular events: an 8-year follow-up of 14719 initially healthy American women," Circulation, vol. 107, no. 3, pp. 391397, 2003.

[5] The Expert Committee on the Diagnosis and Classification of Diabetes Mellitus, "Follow-up report on the diagnosis of diabetes mellitus," Diabetes Care, vol. 26, no. 11, pp. 3160-3167, 2003.

[6] G. S. Hotamisligil, P. Peraldi, A. Budavari, R. Ellis, M. F. White, and B. M. Spiegelman, "IRS-1-mediated inhibition of insulin receptor tyrosine kinase activity in TNF- $\alpha$ - and obesity-induced insulin resistance," Science, vol. 271, no. 5249, pp. 665-668, 1996.

[7] A. D. Pradhan, J. E. Manson, N. Rifai, J. E. Buring, and P. M. Ridker, "C-reactive protein, interleukin 6, and risk of developing type 2 diabetes mellitus," The Journal of the American Medical Association, vol. 286, no. 3, pp. 327-334, 2001.

[8] N. de Rekeneire, R. Peila, J. Ding et al., "Diabetes, hyperglycemia, and inflammation in older individuals: the health, aging and body composition stud," Diabetes Care, vol. 29, no. 8, pp. 1902-1908, 2006.

[9] J. I. Barzilay, L. Abraham, S. R. Heckbert et al., “The relation of markers of inflammation to the development of glucose disorders in the elderly: the Cardiovascular Health study," Diabetes, vol. 50, no. 10, pp. 2384-2389, 2001.

[10] D. J. Freeman, J. Norrie, M. J. Caslake et al., "C-reactive protein is an independent predictor of risk for the development of diabetes in the west of Scotland Coronary Prevention Study," Diabetes, vol. 51, no. 5, pp. 1596-1600, 2002.

[11] M. I. Schmidt, B. B. Duncan, A. R. Sharrett et al., "Markers of inflammation and prediction of diabetes mellitus in adults (Atherosclerosis Risk in Communities study): a cohort study," The Lancet, vol. 353, no. 9165, pp. 1649-1652, 1999.

[12] S. M. Haffner, L. Mykkänen, A. Festa, J. P. Burke, and M. P. Stern, "Insulin-resistant prediabetic subjects have more atherogenic risk factors than insulin-sensitive prediabetic subjects: implications for preventing coronary heart disease during the prediabetic state," Circulation, vol. 101, no. 9, pp. 975-980, 2000.

[13] The Expert Committee on the Diagnosis and Classification of Diabetes Mellitus, "Report of the Expert Committee on the diagnosis and classification of diabetes mellitus," Diabetes Care, vol. 21, no. supplement 1, pp. S5-S19, 1998.

[14] The International Expert Committee, "International expert committee report on the role of the A1C assay in the diagnosis of diabetes," Diabetes Care, vol. 32, no. 7, pp. 1327-1334, 2009.
[15] World Health Organization, World Health Statistics 2011, WHO Press, Geneva, Switzerland, 2011.

[16] World Health Organization Europe, The European Health Report 2009: Health and Health Systems, WHO Regional Office for Europe, Copenhagen, Denmark, 2009.

[17] M. Speeckaert, W. Van Biesen, J. Delanghe et al., "Are there better alternatives than haemoglobin Alc to estimate glycaemic control in the chronic kidney disease population?" Nephrology Dialysis Transplantation, vol. 29, no. 12, pp. 2167-2177, 2014.

[18] Q. Qiao, K. Pyörälä, M. Pyörälä et al., "Two-hour glucose is a better risk predictor for incident coronary heart disease and cardiovascular mortality than fasting glucose," European Heart Journal, vol. 23, no. 16, pp. 1267-1275, 2002.

[19] I. Satman, B. Omer, Y. Tutuncu et al., "Twelve-year trends in the prevalence and risk factors of diabetes and prediabetes in Turkish adults," European Journal of Epidemiology, vol. 28, no. 2, pp. 169-180, 2013.

[20] National Kidney Foundation, "KDIGO 2012 clinical practice guideline for the evaluation and management of chronic kidney disease," Kidney International, vol. 3, no. 1, pp. 8-9, 2013.

[21] D. Aronson, P. Bartha, O. Zinder et al., "Association between fasting glucose and C-reactive protein in middle-aged subjects," Diabetic Medicine, vol. 21, no. 1, pp. 39-44, 2004.

[22] M. Fröhlich, A. Imhof, G. Berg et al., "Association between C-reactive protein and features of the metabolic syndrome: a population-based study," Diabetes Care, vol. 23, no. 12, pp. 1835$1839,2000$.

[23] A. Festa, R. D’Agostino Jr., R. P. Tracy, and S. M. Haffner, "Elevated levels of acute-phase proteins and plasminogen activator inhibitor-1 predict the development of type 2 diabetes: the insulin resistance atherosclerosis study," Diabetes, vol. 51, no. 4, pp. 1131-1137, 2002.

[24] E. Rubio-Martín, F. Soriguer, C. Gutiérrez-Repiso et al., "Creactive protein and incidence of type 2 diabetes in the Pizarra study," European Journal of Clinical Investigation, vol. 43, no. 2, pp. 159-167, 2013.

[25] X. Wang, W. Bao, J. Liu et al., "Inflammatory markers and risk of type 2 diabetes: a systematic review and meta-analysis," Diabetes Care, vol. 36, no. 1, pp. 166-175, 2013.

[26] A. Festa, R. D’Agostino Jr., R. P. Tracy, and S. M. Haffner, "Creactive protein is more strongly related to post-glucose load glucose than to fasting glucose in non-diabetic subjects; the Insulin Resistance Atherosclerosis study," Diabetic Medicine, vol. 19, no. 11, pp. 939-943, 2002.

[27] C. C. Lee, A. I. Adler, M. S. Sandhu et al., "Association of Creactive protein with type 2 diabetes: prospective analysis and meta-analysis," Diabetologia, vol. 52, no. 6, pp. 1040-1047, 2009.

[28] B. Lu, Y. Yang, Z. Yang et al., "Insulin resistance in Chinese patients with type 2 diabetes is associated with C-reactive protein independent of abdominal obesity," Cardiovascular Diabetology, vol. 9, article 92, 2010.

[29] P. M. Ridker, M. Cushman, M. J. Stampfer, R. P. Tracy, and C. H. Hennekens, "Inflammation, aspirin, and the risk of cardiovascular disease in apparently healthy men," The New England Journal of Medicine, vol. 336, no. 14, pp. 973-979, 1997.

[30] M. Fisher, M. Cushman, V. Knappertz, and G. Howard, "An assessment of the joint associations of aspirin and statin use with C-reactive protein concentration," American Heart Journal, vol. 156, no. 1, pp. 106-111, 2008.

[31] S. E. Kahn, B. Zinman, S. M. Haffner et al., "Obesity is a major determinant of the association of C-reactive protein levels and 
the metabolic syndrome in type 2 diabetes. ADOPT Study Group," Diabetes, vol. 55, no. 8, pp. 2357-2364, 2006.

[32] A. D. Pradhan, J. E. Manson, J. E. Rossouw et al., "Inflammatory biomarkers, hormone replacement therapy, and incident coronary heart disease: prospective analysis from the women's health initiative observational study," The Journal of the American Medical Association, vol. 288, no. 8, pp. 980-987, 2002.

[33] T. Wu, J. P. Dorn, R. P. Donahue, C. T. Sempos, and M. Trevisan, "Associations of serum C-reactive protein with fasting insulin, glucose, and glycosylated hemoglobin: the Third National Health and Nutrition Examination Survey, 1988-1994," American Journal of Epidemiology, vol. 155, no. 1, pp. 65-71, 2002.

[34] A. G. Niehoff, T. W. van Haeften, N. C. Onland-Moret, C. C. Elbers, C. Wijmenga, and Y. T. Van Der Schouw, "C-reactive protein is independently associated with glucose but not with insulin resistance in healthy men," Diabetes Care, vol. 30, no. 6, pp. 1627-1629, 2007.

[35] S. Ilhan, Y. Tutuncu, S. Gedik et al., "Phenotypes and biochemical characteristics of new diabetes patients diagnosed based upon different criteria: HbAlc recognises people at a more advanced diabetic stage," Diabetes, vol. 62, supplement 1, abstract A277, pp. S121-S122, 2013.

[36] C. den Engelsen, P. S. Koekkoek, K. J. Gorter, M. van den Donk, P. L. Salomé, and G. E. Rutten, "High-sensitivity Creactive protein to detect metabolic syndrome in a centrally obese population: a cross-sectional analysis," Cardiovascular Diabetology, vol. 11, article 25, 2012.

[37] E. Oda, K. Oohara, A. Abe et al., "The optimal cut-off point of C-reactive protein as an optional component of metabolic syndrome in Japan," Circulation Journal, vol. 70, no. 4, pp. 384$388,2006$. 


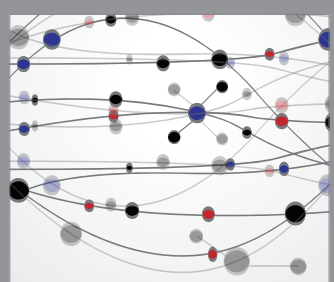

The Scientific World Journal
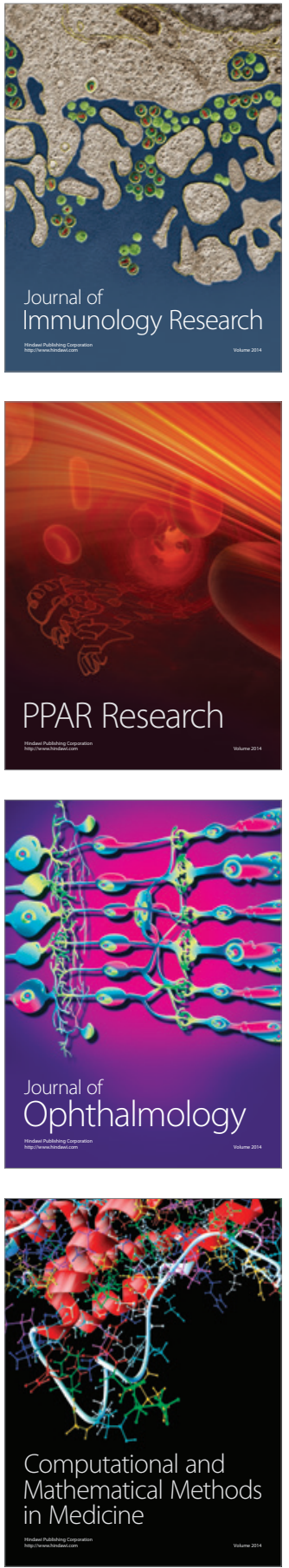

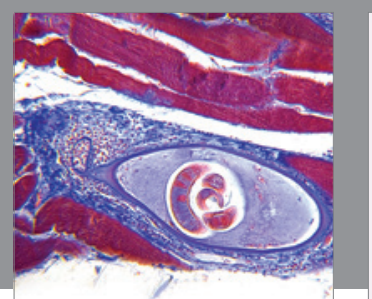

Gastroenterology Research and Practice

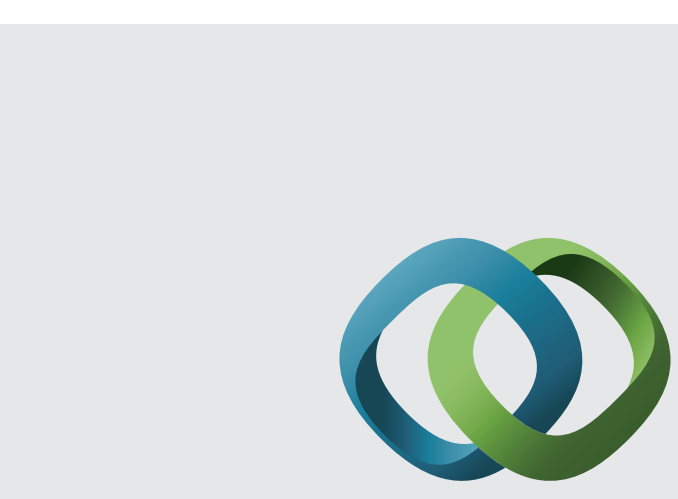

\section{Hindawi}

Submit your manuscripts at

http://www.hindawi.com
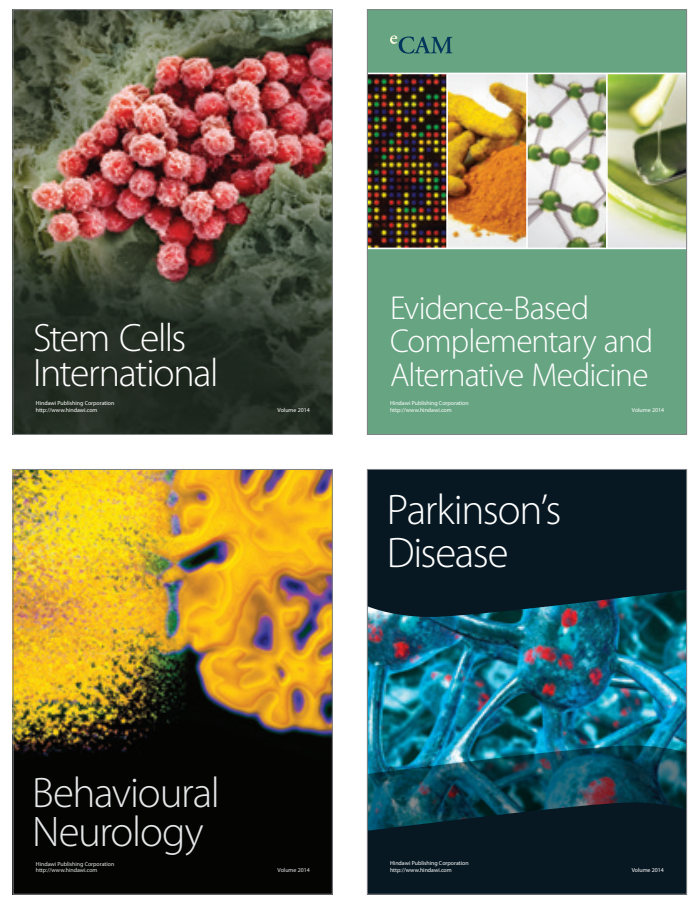
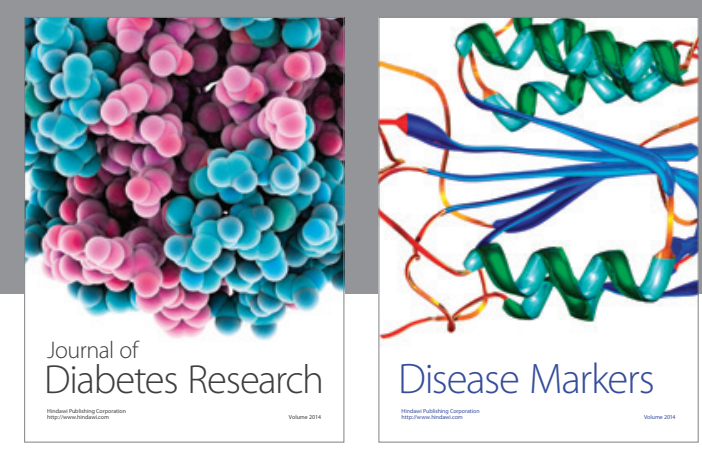

Disease Markers
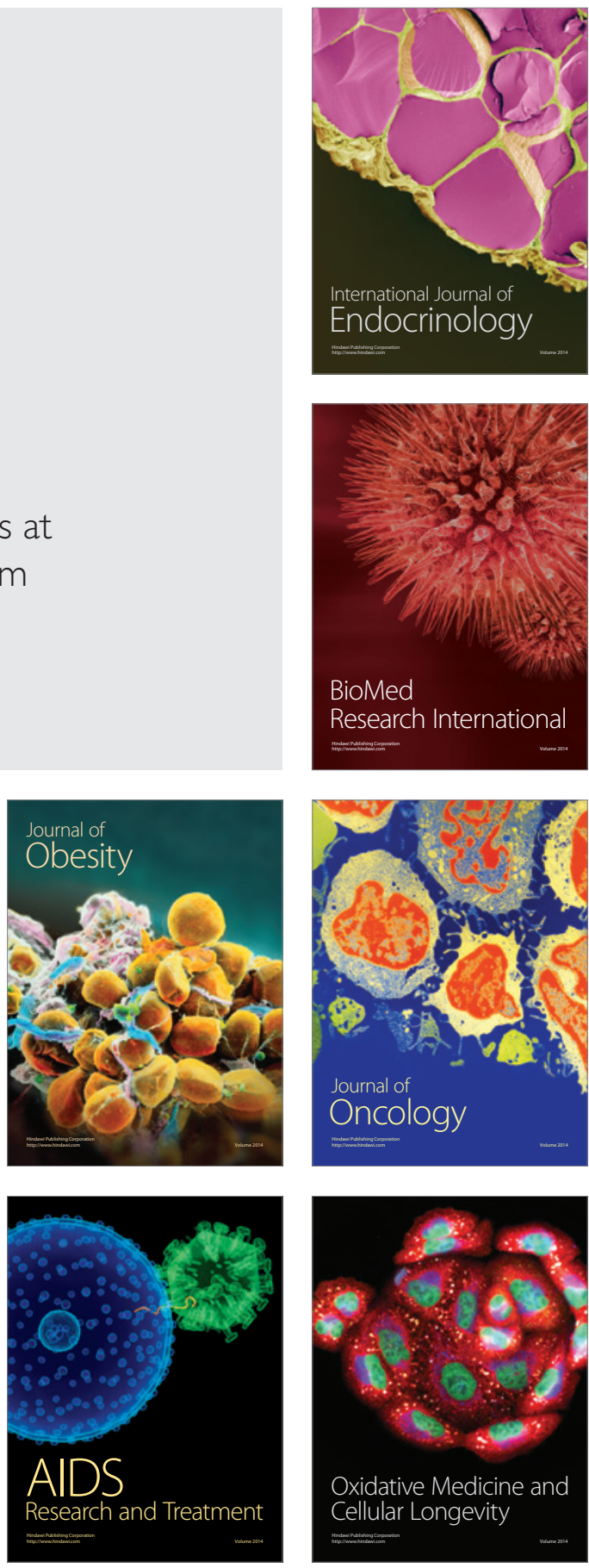